\title{
Use of two vertical injectors in place of a horizontal injector to improve the efficiency and stability of THAI in situ combustion process for producing heavy oils
}

\author{
Muhammad Rabiu Ado ${ }^{1}$ (D)
}

Received: 5 August 2021 / Accepted: 19 October 2021 / Published online: 30 October 2021

(c) The Author(s) 2021

\begin{abstract}
The current commercial technologies used to produce heavy oils and bitumen are carbon-, energy-, and wastewater-intensive. These make them to be out of line with the global efforts of decarbonisation. Alternative processes such as the toe-to-heel air injection (THAI) that works as an in situ combustion process that uses horizontal producer well to recover partially upgraded oil from heavy oils and bitumen reservoirs are needed. However, THAI is yet to be technically and economically well proven despite pilot and semi-commercial operations. Some studies concluded using field data that THAI is a low-oilproduction-rate process. However, no study has thoroughly investigated the simultaneous effects of start-up methods and wells configuration on both the short and long terms stability, sustainability, and profitability of the process. Using THAI validated model, three models having a horizontal producer well arranged in staggered line drive with the injector wells are simulated using CMG STARS. Model A has two vertical injectors via which steam was used for pre-ignition heating, and models B and C each has a horizontal injector via which electrical heater and steam were respectively used for pre-ignition heating. It is found that during start-up, ultimately, steam injection instead of electrical heating should be used for the preignition heating. Clearly, it is shown that model A has higher oil production rates after the increase in air flux and also has a higher cumulative oil recovery of $2350 \mathrm{~cm}^{3}$ which is greater than those of models B and C by $9.6 \%$ and $4.3 \%$ respectively. Thus, it can be concluded that for long-term projects, model A settings and wells configuration should be used. Although it is now discovered that the peak temperature cannot in all settings tell how healthy a combustion front is, it has revealed that model A does indeed have far more stable, safer, and efficient combustion front burning quality and propagation due to the maintenance of very high peak temperatures of mostly greater than $600{ }^{\circ} \mathrm{C}$ and very low concentrations of produced oxygen of lower than $0.4 \mathrm{~mol} \%$ compared to up to $2.75 \mathrm{~mol} \%$ in model C and $1 \mathrm{~mol} \%$ in model B. Conclusively, since drilling of, and achieving uniform air distribution in horizontal injector (HI) well in actual field reservoir are costly and impracticable at the moment, and that electrical heating will require unphysically long time before mobilised fluids reach the HP well as heat transfer is mainly by conduction, these findings have shown decisively that the easy-and-cheaper-to-drill two vertical injector wells configured in a staggered line drive pattern with the horizontal producer should be used, and steam is thus to be used for pre-ignition heating.
\end{abstract}

Keywords In situ combustion (ISC) · Enhanced oil recovery (EOR) · Bitumen/heavy oil/tar sand · Reservoir simulation · Toe-to-heel air injection (THAI) · Thermal EOR

\section{Introduction}

There is no doubt that the corona virus pandemic has hugely affected the global energy and thus economic system. The

Muhammad Rabiu Ado

mado@kfu.edu.sa

1 Department of Chemical Engineering, College of Engineering, King Faisal University, P.O. Box 380, Al-Ahsa 31982, Kingdom of Saudi Arabia effect might be felt for many years to come especially that it is yet to be fully under controlled. However, governments and businesses are adapting as the race to vaccinate all humans is on. As a result, economic activities together with use of oils will increase. Based on the analysis of the 
most recent International Energy Agency's (IEA's) projections about increase in oil demand, it is found that around 770 billion barrels of oil are needed from now to year 2040 (International Energy Agency 2020). However, the British Petroleum (BP) 2020 statistical review of world energy has shown that the total proved reserves of recoverable conventional and unconventional oils are 1734 billion barrels globally as at the end of 2019 (British Petroleum (BP) 2020). Out of that, a total of $70 \%$ of the 1734 billion barrels of oil are composed of unconventional oils (i.e. heavy oils and bitumen) (Elahi et al. 2019; Guo et al. 2016; Liu et al. 2019). This implies that conventional light oils make up the remaining $30 \%$ of the recoverable resources (i.e. 520.2 billion barrels). Putting all of the above together, if only all of the light oils are to be used, they are not enough to cater for the demand from now to the next two decades. Therefore, it cannot but be concluded that at least 249.8 billion barrels of heavy oils and bitumen are needed to satisfy the demand from now to the next 20 years. Furthermore, without new discoveries of recoverable light oils reservoirs, beyond 2040, all our petroleum consumption must come from the heavy oils and bitumen. This is so because still there is no alternative capable of meeting the increasing demand from petrochemical and transportation sectors. Also, plastics and other medical equipment must continuously be made especially in this age where virus is rapidly being transmitted throughout the world. Heavy oils and bitumen are very sticky and most of them do not flow under natural reservoir conditions due to their very high viscosity of up to $1.2 \times 10^{2} \mathrm{cP}$ and API gravity of even lower than $8^{\circ}$ API depending on the reservoir (Attanasi and Meyer 2010; Hein 2017; Li et al. 2020; Meyer et al. 2007; Zhang et al. 2019). Thus, the urgent need for technologies for energy-efficient and environmentally friendly upgrading and production of heavy oils and bitumen cannot be overstated. However, it must be stressed that the current commercial steam-based extraction and production methods are carbon and energy intensive. More so, these processes do not permanently alter the physicochemical properties of the oils such that even if the produced oil is returned to the typical reservoir temperature, it should not loss its mobility due to increase in viscosity and density. Multiple studies have shown that the most popular steambased process, the steam-assisted gravity drainage (SAGD), cannot be applied widely as production from certain reservoirs is uneconomical or unsafe or both (Gates 2010; Gates and Larter 2014; Ma and Leung 2020; Mokrys and Butler 1993; Paitakhti Oskouei et al. 2011; Shah et al. 2010; Shi et al. 2017; Turta and Singhal 2004; Zhao et al. 2013, 2014). Additionally, steam-based processes are water intensive as they handle very large quantity of water and wastewater. And in fact, some of the SAGD operations have been shown to not be net energy producers (Gates and Larter 2014). In-situcombustion-type (ISC-type) processes hold considerable promise as they do not suffer from any disadvantages of the steam-based processes. However, it is worth pointing out at this stage that the operation of the ISC-type processes is highly complex because they are composed of simultaneous multiphase and multicomponent reactive transport systems in porous media.

Toe-to-heel air injection (THAI) is an in-situ-combustion-type process that uses horizontal producer (HP) well in combination with a horizontal injector (HI) to form HIHP configuration in a staggered line drive pattern or either a single vertical injector (VI) well to form VIHP arrangement in a direct line drive pattern or double vertical injectors (2VI) to form 2VIHP wells configuration in a staggered line drive pattern (Greaves et al. 1993; Greaves and Al-Shamali 1996; Xia et al. 2002). HIHP and 2VIHP configurations were respectively only used in laboratory experiments, whilst VIHP was used in both the laboratory experiments and field operations. Since the issue of well configurations is discussed briefly here, I shall discuss it in more details later since partly, it is one of the aims of this work. At experimental level, during start-up phase, different fluids (such as hot nitrogen or steam) or electrical heaters are used to prepare the inlet zone of the injector(s) so that enough heaviest fraction of the oil is left to be burnt as coke. Also, the pre-ignition heating is performed to establish fluids communication between the wells (Ado 2020a; Greaves et al. 1999; Rabiu Ado 2017; Xia and Greaves 2002, 2006). Study by Liang et al. (2012) has stressed the importance of optimum start-up so that the combustion front should always be maintained as forward leaning rather than back-slanting. Immediately the pre-ignition heating cycle (PIHC) is over, air injection commenced which is then followed by electrical ignition. Continual injection of air results in propagation and expansion of the combustion zone in all the three directions, leading it to become conical in shape with narrow end pointing downward towards toe of the HP well. In terms of the physicochemical processes, at least five distinct-property zones develop right from the combustion front up to the heel of the HP well. Ahead of the combustion front lies the coke zone where high-temperature oxidation (HTO) reaction which fuels the process takes place. There forward lies the thermal cracking zone in which coke is deposited and lighter components are produced which then mixed with mobile oil in it is zone (i.e. MOZ). Between thermal cracking zone and MOZ, a steam zone exists which is formed due to both vaporisation of reservoir native water and from the combustion gases. Ahead of MOZ lies the cold oil zone (COZ) where not enough heat has reached to alter flow-ability or physical properties of the oil in that zone (Rabiu Ado et al. 2017, 2018; Xia et al. 2005). Although the THAI process is largely far away from being understood as a result of the absence of general and reservoir-specific design procedures and operation manuals, laboratory experimental studies have consistently shown that 
the process's recovery factors are up to $85.5 \%$ of oil originally in place (OOIP), that permanent physical and chemical alterations were achieved as shown in terms of increase in API gravity by up to an average of $10^{\circ}$ points in addition to that of the original bitumen, and that viscosity reduction down to $50 \mathrm{mPas}$ was achieved (Greaves et al. 1999; Xia and Greaves 2002, 2006; Xia et al. 2002). Other advantages of the THAI process as found experimentally and through numerical simulation include generation of large amount of hydrogen gas which is partly used for hydro-conversion and partly produced with the combustion gases, large quantity of sulphur and heavy metals are locked in the reservoir showing that the process is relatively environmentally friendlier, and since the process uses short-distance displacement mechanism to produce mobilised upgraded oil, realisation of return on investment will be very fast compared to in the other processes (Greaves et al. 2008; Turta and Singhal 2004; Xia et al. 2005). Another import merit of the THAI process is the ease with which an annular layer of hydro-treating catalyst can be added around the HP well so that apart from thermal cracking upgrading, additional upgrading is achieved catalytically. Ado et al. (2021) are the first to conduct multiple research on numerically simulating in situ combustion process coupled with in situ catalytic upgrading process to form a single process referred to as THAI-CAPRI.

At field scale, two THAI projects were operated by Petrobank (later called Touchstone). In the first pilot study, upgraded oil was produced albeit at smaller production rates. However, there was excessive sand production that considerably affected the economic performance of the process. Also, there was no direct relationship between injected air and produced oil (Petrobank 2007, 2008, 2009). The company considered the learning from the project a technical success despite their total failure to economically prove the process. Lack of comprehensive design and operation procedures are also part of the reasons why the technical validity of the process is only partial. Moving forward, the company started a semi-commercial operation in Kerrobert, Canada, where oil production rates were initially profitable before, may be, air channelling into the bottom water zone, or into the overlaying gas reservoirs or both, destabilised the combustion zone, leading to fingering and loss of control. This caused oil production rates to decrease to the extent that the company had to dispose of the project due to uncontrollable operating losses. Part of the reasons why healthily-structured combustion front was not established could be due to insufficient PIHC and/or improper design since their designs were based on reservoir simulations using kinetics that were not up-scaled and thus could well result in erroneous designs as has been found out by Ado (2020b c, d). These two Canadian projects have therefore validated the THAI process only partially technically. In terms of the process taking place as a major heavy oils and bitumen upgrading and producing technology, the economic validity of the process must be fully established. There are around three studies published in 2020 about the Kerrobert THAI project. All of them concluded to the following effect: there is an air injection rate limit beyond which no gain in incremental oil production rates can be obtained, and therefore, air injection rate must not be more than 20,000 $\mathrm{Sm}^{3} /$ day (Wei et al. 2020a, b). However, this conclusion is very weak because numerical simulation studies, which are under review, have shown that air could be channelling into the bottom water zone thereby causing excessive water production (i.e. high water cuts) as observed by Turta et al. (2020). Also, there were shale inter-layers in the reservoir that might have caused some of the oxidant to be bypassing the combustion front and be moving into the upper permeable rock especially if it did not provide total effective sealing (Ado et al. 2019). Also, the large air injection rates could be part of the reasons as one of the pilot studies in China has shown that optimum air flux must lie between 0.15 and $0.3 \mathrm{Sm}^{3} / \mathrm{m}^{2} \mathrm{~h}$ (Xi 2016) and still the combustion will be in an HTO mode. Ado (2020e) conducted numerical simulations and found that air injection flux must be kept to optimally minimum value of $0.35 \mathrm{Sm}^{3} /$ $\mathrm{m}^{2} \cdot \mathrm{h}$, which is similar to the conclusion drawn by Wei et al. (2020b), to avoid channelling, fingering, and bypassing of combustion front. Also, Ado has shown that using pure oxygen as the injected oxidant results in large increase in cumulative oil recovery of at least 3.85\% OOIP (Ado 2021). Apart from the Canadian THAI projects, Turta (2018) claimed that there are THAI pilot studies in China and in India. The information available about one of the projects in China indicated that oil production rates of up to 400 barrels per day are being achieved and that the process operates in HTO mode with very high volumetric sweep efficiency and recovery factor (Xi 2016). In all of these projects, Turta (2018) found that all the vertical injector/horizontal producer (VIHP) well pairs were or are configured in direct line drive (DLD) pattern. This implies that the VI well is on the same mid-plane as the HP well even though the former is offset axially and is located vertically above the latter. The DLD configuration is thought to not provide high oil production rates due to the inherently smaller volume of the combustion front. Also, DLD arrangement leads to premature oxygen production and eventually breakthrough. Since there are no conclusive studies about the best well configuration and how it will affect the stability of the combustion front and thus the oil production rates, the studies that attempted to provide the studies, albeit non-exhaustive, merit reviewing here.

The first experimental study of the effect of wells configuration on the performance of the THAI process was conducted by Xia et al. (2002). They concluded that HIHP is the best configuration for realising efficiently rapid start-up and achieving stable combustion front advancement despite the fact that they indicated that it is not a practical design

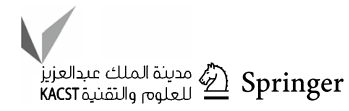


in actual field operation and that they did not report about the stability of the process over the lifetime of the experiment. They also found that VIHP DLD pattern has the lowest recovery as a result of oxygen breakthrough resulting in early extinguishment of the combustion front. However, that study did not explain if in the long term, the stability achieved in the HIHP arrangement is sustained up to the end of operating time. Also, this study did not investigate the effect of start-up methods on the various wells configurations. That is to say, with VIHP arrangement, is injecting steam, hot nitrogen, or electrical heating during the PIHC going to provide and results in sustaining stable combustion front propagation throughout the duration of the experiment. Also, their study did not provide information about the performance of 2VIHP configuration both during start-up and over full operation period. Fatemi et al. (2009) performed numerical simulation studies to investigate the optimum well pairs configurations for the THAI process. They found that 2VIHP and VIHP are the best respective arrangement in terms of many performance indicators, such as oil rates, ultimate oil recoveries, produced combustion gases, and volumetric sweep. However, the authors conducted the study using electrical heating to condition the inlet zone of the 3D combustion cell and probably to establish fluid communication between the two wells. That means, they did not consider the fact that if another preignition heating method is used, for example using steam, how are the different wells configurations going to affect the performance of the THAI process throughout the operation time (i.e. from start-up to shutdown). Furthermore, none of the two studies used steam for the PIHC despite the fact that it is the most abundant fluid that is used in heavy oils and bitumen mobilisation and production. One of the latest studies by Zhao et al. (2018) investigated about the influence of injector-producer spacing on the performance of the THAI process. They concluded that the spacing should be optimised for actual field operation design which is as expected. However, the study also used electrical heater to pre-heat the inlet zone of the VI well and subsequently achieve ignition. Steam, which is used in the field for PIHC, should have been used because the flow pattern and the shape of the combustion zone are partly determined by the method used for the PIHC. A recently published study by Ado (2021) has shown that comparatively, 2VIHP is far more efficient, stable, and profitable than VIHP configuration. However, that study did not check what will happen if a different PIHC method is used instead of steaming. Also, that study work did not operate the THAI process up to the cut-off point beyond which continual operation is either unsafe, uneconomical, or both.

From the above literature survey, none of the studies is conclusive, and thus, it cannot but be concluded that the THAI process is far from being fully understood in terms of start-up phase, operation phase, and shutdown stage. Here, stress is placed on the start-up phase because in most cases, if not all, it is the ultimate determiner of the success or otherwise of the THAI process. It then naturally follows that full understanding of optimal process design and operating conditions is necessary if the massive economical promise of the THAI process is to be fully realised. Thus, to move forward, design and operating manuals are essentially required as outlined in an unpublished review by Ado (2021). Additionally, from the above literature review and in order to develop a standard start-up procedure, it cannot but be concluded that the method of starting-up the operation of the THAI process must consider optimal operation by ensuring stable combustion initiation and its front propagation, safety, and profitable oil production rates are maintained initially and throughout the lifetime of the project. Thence, among the many process design factors that must be accurately and optimally predicted and set prior to full field deployment are the wells configurations and the method of pre-ignition heating. As a consequence, the aim of this work is to investigate the performance of the THAI process based on wells configurations and start-up methods, and it is stability over the lifetime of the operation by developing three numerical models based on a validated numerical model that was developed and simulated using computer modelling group $(\mathrm{CMG})$ thermal reservoir simulator, STARS, which is selected because it is one of the major thermal reservoir simulators being used industrially and academically to investigate and predict performance of various thermal and even non-thermal enhanced oil recovery processes. These three models which are referred to as $\mathrm{A}, \mathrm{B}$, and $\mathrm{C}$ respectively and which are validated and reported in Ado (2020a), are:

A. Two vertical injectors/horizontal producer (2VIHP) wells pair model that saturated steam at $226{ }^{\circ} \mathrm{C}$ and $2600 \mathrm{kPa}$ was used during its pre-ignition heating cycle (PIHC).

B. Horizontal injector/horizontal producer (HIHP) wells pair model that electrical heating at rate of $2115 \mathrm{~J} \mathrm{~min}^{-1}$ was used during the PIHC, and

C. Horizontal injector/horizontal producer (HIHP) wells pair model that saturated steam at $226^{\circ} \mathrm{C}$ and $2600 \mathrm{kPa}$ was used during the PIHC.

For model B, in accordance with the experiment (Xia and Greaves 2002), electrical heater/ignitor was used with heating rate in each of the 17 gridblocks of $35.25 \mathrm{~W}$ to heat the inlet zone of the sandpack, establish communication with the HP well, and initiate combustion. The pre-ignition electrical heating was conducted for $28 \mathrm{~min}$ and ignition was achieved over 2 min. For models A and C, steam containing the equivalent amount of heating rate in model $\mathrm{B}$ was injected at a rate of $21.17 \mathrm{~cm}^{3} \mathrm{~min}^{-1}$ cold water equivalent (CWE) for a period of $28 \mathrm{~min}$ in each of the two models. 
Then, in each model, electrical heater/ignitor was used for 2 min to further increase the temperature of the inlet zone of the sandpack and subsequently to initiate the combustion. More information about the method will be discussed under the methodology section.

This study has shown conclusively that the use of $2 \mathrm{VI}$ wells together with steaming during the PIHC is by far more efficient, safer, and more economical due to higher cumulative oil recovery. More so, since drilling of, and achieving uniform air distribution in horizontal injector (HI) well in actual field reservoir are costly and impracticable at the moment, and that electrical heating will require unphysically long time before mobilised fluids reach the HP well as heat transfer is mainly by conduction, these findings have shown decisively that the easy-and-cheaper-to-drill vertical injector wells arranged with HP well in a staggered line drive (SLD) configuration should be used in actual field reservoir.

\section{Numerical simulation models development}

In this work, ideal homogenous sandstone bottom-water-free Athabasca-bitumen-type reservoir is simulated at experimental scale. Therefore, the model reservoir parameters and properties are those of the Canadian Athabasca bitumen with exception of those parameters, such as absolute permeability, fluids saturations, temperature, and pressure, that depend on the sand packing and the laboratory. The numerical model dimensions are similar to that reported experimentally (Xia and Greaves 2002) and to the three different numerical models validated against the former (Ado 2020a). All the three numerical models were constructed using the computer group modelling (CMG) reservoir simulator, i.e. the CMG STARS. The models dimensions, wells configurations, and the number of gridblocks in which the reservoir is discretised into 30 in $\mathbf{i}^{\text {th }}$ direction by 19 in $\mathbf{j}^{\text {th }}$ direction by 7 in $\mathbf{k}^{\text {th }}$ direction are shown in Fig. 1 . It is very important at this stage to specify that model $\mathrm{A}$ is the one shown in Fig. 1a, whilst models B \& $\mathrm{C}$ are the ones shown in Fig. 1b. The difference between B \& $C$ is the use of electrical heating in the former and use of steam in the latter during the PIHC. This simulator allows discretised wellbore (DW) option to enable the dynamic nature of the multicomponent, multiphase fluid flow and heat transport to be numerically simulated after discretisation. The DW, which represents the HP well, and discretised reservoir reactive transport equations are then solved simultaneously by the use of parallel processing solver called PARASOL. Each model was run on a computer that has 16 cores and 32 threads. However, the STARS allows only 4 cores for the parallel computation, and therefore, only $25 \%$ of the threads (i.e. 8 threads) were used. Onwards, the simulation cannot be run without fully defining the boundary and initial conditions. Also, operating conditions and reservoir properties, such as porosity and permeability, etc., must be specified.

\section{Reservoir petro-physical parameters}

The porosity, absolute permeabilities, and initial fluids saturations, which are those of the typical Athabasca bitumen, are shown in Table 1. These parameters were also used in the validated models presented by Rabiu Ado (2017) and Ado (2020a). The relative permeability curves for oil/water and gas/oil are shown in Fig. 2.

\section{Pressure, density, and temperature (PpT) properties of the bitumen}

Since heavy oils and bitumen are a mixture of so many compounds, it is impractical to represent all the compounds individually. As a result, pseudo-components are used which are a cut of the bitumen, for example, over a specified boiling temperature range. In this work, and also in accordance with the validated model (Ado 2020a) that is being used in this work, two oil pseudo-components are used to represent the whole bitumen. These are called HEAV oil and LITE oil. Table 2 which is extracted from Ado (2020a) shows the critical parameters, density, molecular weight, composition, acentric factor, and normal boiling points of the pseudo-components.

The temperature-and-pressure-dependent $K$ values needed to represent and account for vapour-liquid equilibrium and the viscosity of the individual oil pseudo-component can be found in Ado (2020a) as they are the same. Thus, it is not worth reproducing them here so as to conserve space.

\section{Kinetics scheme and it is parameters}

In all the three models, improved modified kinetics scheme which is very well validated against experimental results and referred to as "model G" in Ado (2020a) is used together with it is Arrhenius parameters. This kinetics scheme is also fully detailed in Ado (2020c) where it is described as "split conversion kinetics scheme (SCKS)" due to the fact that the concentrations of the thermal cracking reactions' products are heavily dependent on their selected stoichiometric coefficients. This SCKS is highly indeterminable because there are infinite number of possible combinations to obtained atom- and mass-wised balanced chemical reaction. For example, the SCKS is expressed as HEAV Oil $\rightarrow(x)$ LITE Oil $+(y)$ Coke such that $x$ and $y$ as the stoichiometric coefficients can have any numbers. This, therefore, ultimately increases the number of unknowns in the reactive transport equations. As a result, and for the sake of clarity and knowledge advancement and sharing, SCKS-type schemes cannot

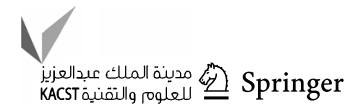


Fig. 1 Three-dimensional laboratory-scale combustion cell showing the dimensions, wells configurations, and the cardinal directions of $\mathbf{i}, \mathbf{j}, \mathbf{\&} \mathbf{k}$. a Shows 2VIHP arrangement in staggered line drive pattern, and b shows HIHP arrangement in staggered line drive pattern

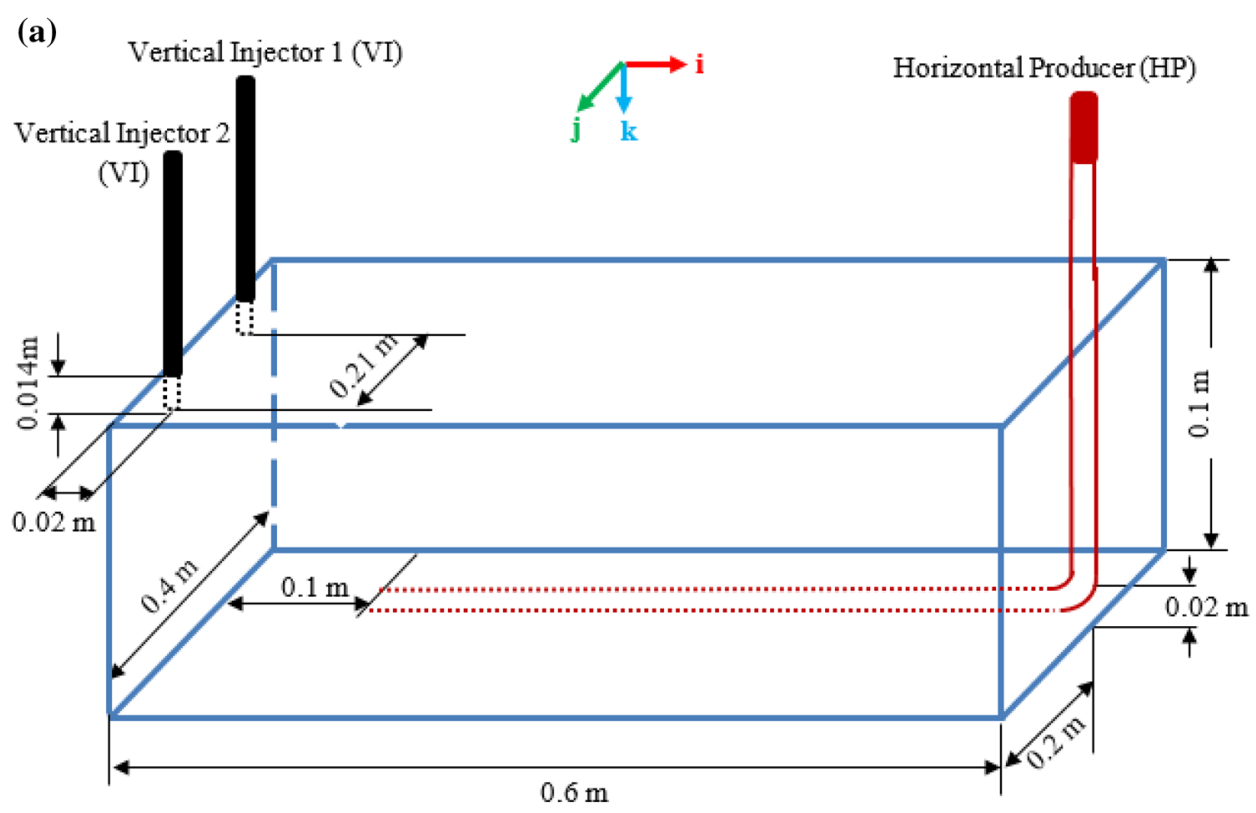

(b) Horizontal Injector (HI)

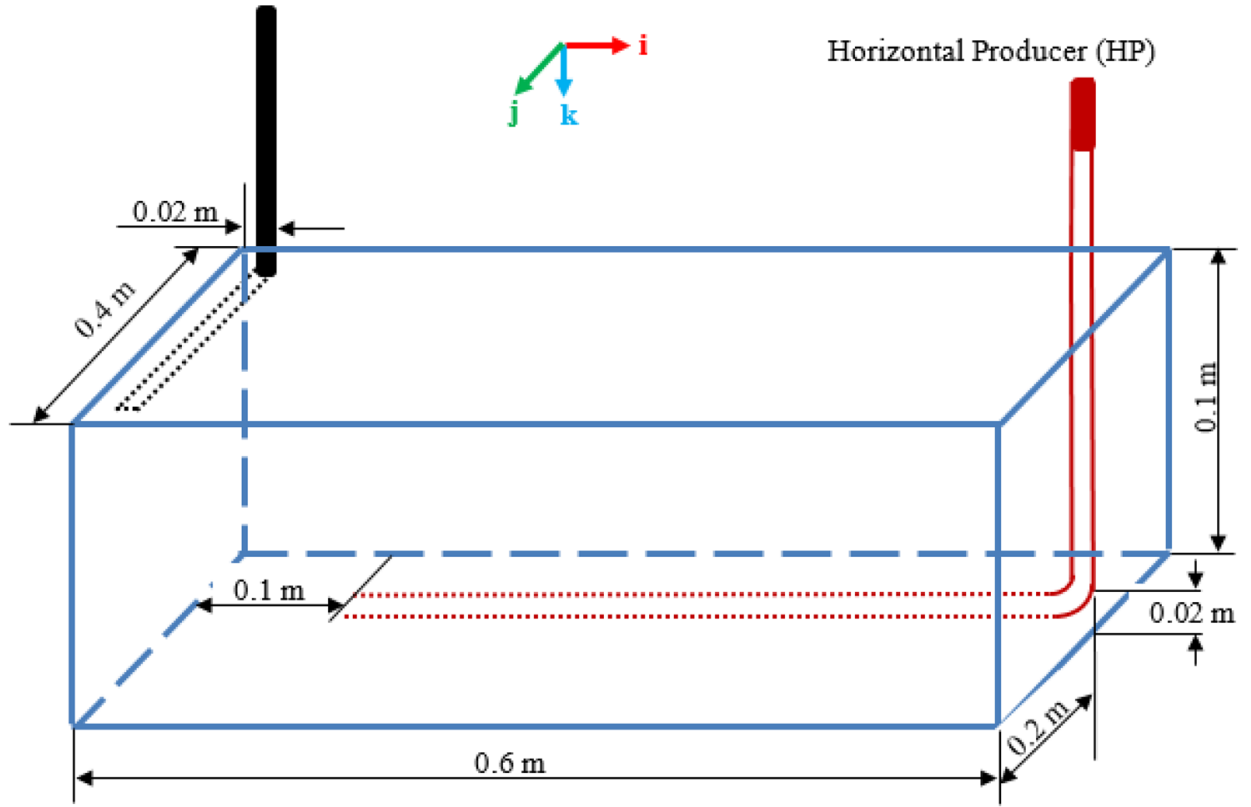

Table 1 Porosity, absolute permeabilities, and initial fluid saturations in the reservoir

\begin{tabular}{ll}
\hline Reservoir property & Value \\
\hline Porosity & 0.34 \\
Absolute vertical permeability $(\mathrm{mD})$ & 3450 \\
Absolute horizontal permeability $(\mathrm{mD})$ & 11,500 \\
Oil saturation, $S_{\mathrm{o}}$ & 0.85 \\
Water saturation, $S_{\mathrm{w}}$ & 0.15 \\
Gas saturation, $S_{\mathrm{g}}$ & 0.00 \\
\hline
\end{tabular}

be systematically up-scaled to study field scale scenarios and give meaningful predictions [please see Ado $(2020 \mathrm{~b}$ c) for full details]. However, since it is very well validated and is able to provide physically meaningful predictions at laboratory scale, it is used in this study as can be seen in Table 3 .

Note that the other components, in addition to the two oil pseudo-components, are shown in the balanced chemical reactions in Table 3. $\mathrm{O}_{2}=$ oxygen gas in air; $\mathrm{H}_{2} \mathrm{O}$ is water vapour in the combustion gases; $\mathrm{CH}=$ Coke which is the carbonaceous immobile fraction responsible for operation in HTO mode; $\mathrm{CO}_{1.94}$ is the combination of carbon oxides (i.e. $\mathrm{CO}_{2}$ and $\mathrm{CO}$ ) so that lower number of 
Fig. 2 Relative permeability curves for the Canadian Athabasca bitumen for a oil/ water, and $\mathbf{b}$ gas/oil (a)

Oil-Water Relative Permeability Curve

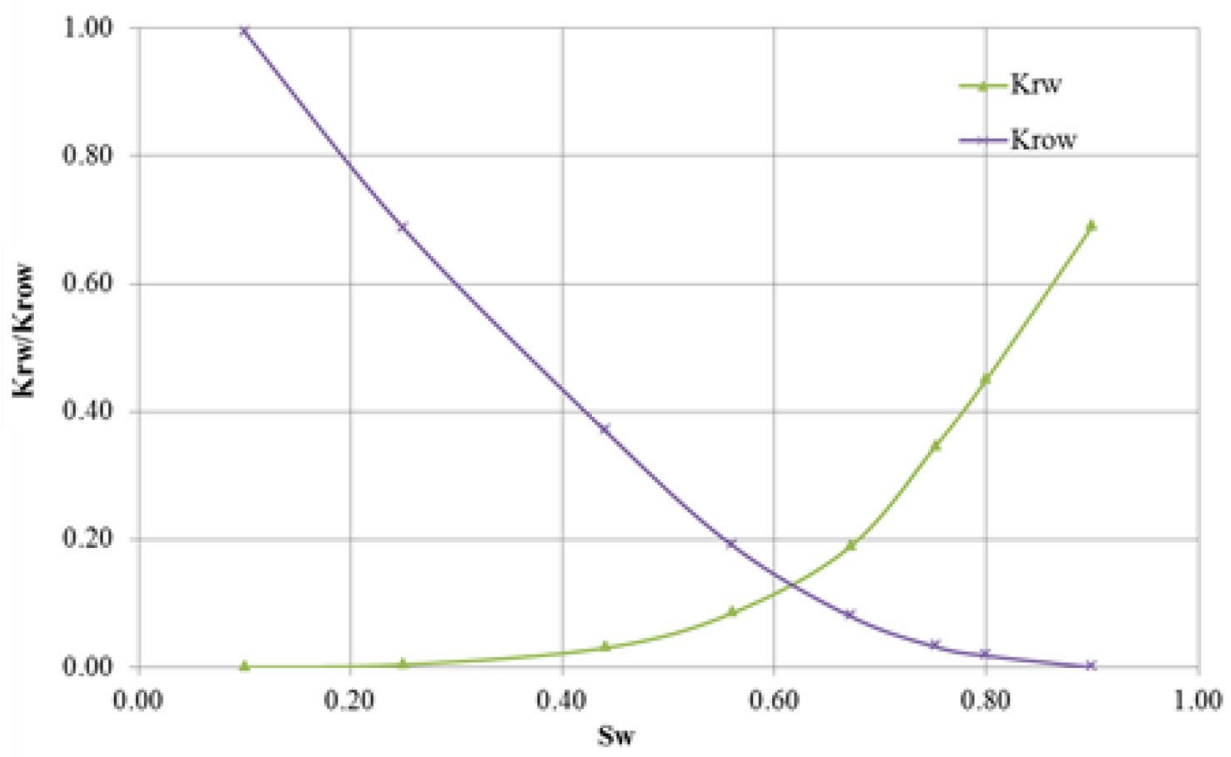

(b)

Gas-Oil Relative Permeability Curve

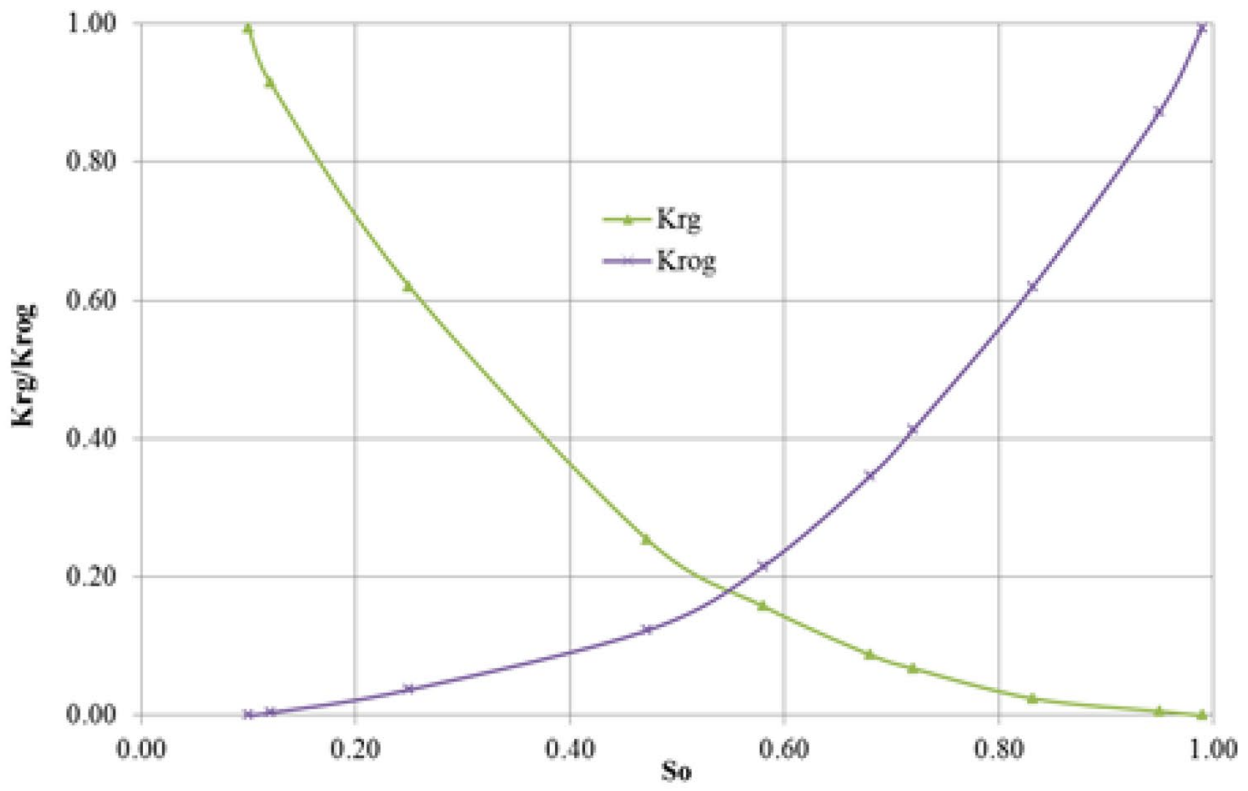

Table 2 PVT data as reported in Ado (2020a)

\begin{tabular}{lllllrrr}
\hline Components & Split $(\mathrm{mol} \%)$ & $\mathrm{RMM}(\mathrm{g} / \mathrm{mol})$ & $P_{\mathrm{c}}(\mathrm{kPa})$ & $T_{\mathrm{c}}\left({ }^{\circ} \mathrm{C}\right)$ & $\rho\left(\mathrm{kg} / \mathrm{m}^{3}\right)$ & $\omega$ & $T_{\mathrm{B}}\left({ }^{\circ} \mathrm{C}\right)$ \\
\hline LITE oil & 36.47 & 170.00 & 2305.95 & 425.16 & 903.80 & 0.48 & 246.60 \\
HEAV oil & 63.53 & 878.00 & 1031.29 & 780.00 & 1012.07 & 1.45 & 711.00 \\
\hline
\end{tabular}

components are used to lessen the number of equations that have to be solved.

\section{Initial and boundary conditions}

Initially inside the HP well, oil saturation is assigned a value of 0 in each model. This is justified because at the native reservoir condition, the bitumen is immobile and none of 
Table 3 Thermal cracking and combustion reactions with their Arrhenius parameters as reported in Ado (2020a)

\begin{tabular}{llll}
\hline & Frequency factor $\left(\mathrm{min}^{-1}\right)$ & $\begin{array}{l}\text { Activation } \\
\text { energy }(\mathrm{kJ} / \mathrm{mol})\end{array}$ & $\begin{array}{l}\text { Heat of reac- } \\
\text { tion }(\mathrm{kJ} / \mathrm{mol})\end{array}$ \\
\hline $\begin{array}{l}\text { Thermal cracking reaction } \\
\mathrm{HEAV} \rightarrow 1.6 \mathrm{LITE}+46.6 \mathrm{Cok}\end{array}$ & $1.50 \times 10^{9}$ & 99.00 & 0.00 \\
$\begin{array}{l}\mathrm{C} \text { ombustion reactions } \\
\mathrm{HEAV}+80 \mathrm{O}_{2} \rightarrow 26.7 \mathrm{H}_{2} \mathrm{O}+68.7 \mathrm{CO}_{1.94}\end{array}$ & $1.81 \times 10^{11} \mathrm{kPa}^{-1}$ & 138.00 & $5.91 \times 10^{2}$ \\
$\mathrm{LITE}+19 \mathrm{O}_{2} \rightarrow 14.5 \mathrm{H}_{2} \mathrm{O}+11.8 \mathrm{CO}_{1.94}$ & $1.81 \times 10^{12} \mathrm{kPa}^{-1}$ & 138.00 & $4.91 \times 10^{2}$ \\
$\mathrm{CH}+1.22 \mathrm{O}_{2} \rightarrow 0.5 \mathrm{H}_{2} \mathrm{O}+\mathrm{CO}_{1.94}$ & $8.60 \times 10^{7} \mathrm{kPa}^{-1}$ & 123.00 & $3.65 \times 10^{2}$ \\
\hline
\end{tabular}

it has entered into the HP well prior to heat addition. The initial reservoir temperature and pressure are respectively $27^{\circ} \mathrm{C}$ and $290 \mathrm{kPa}$ which are in accordance with the experimental setting against which the model is validated (Xia and Greaves 2002). All over the combustion cell, in each model, no flow boundary condition is assigned with exception of flows through injector(s) and producer. The HP well in each model was assigned two boundary conditions, namely maximum liquid production rate of $25 \mathrm{~cm}^{3} \mathrm{~min}^{-1}$ and minimum bottom hole pressure of $170 \mathrm{kPa}$. The simulator uses either of the two depending on which one is violated. For the HI or 2VI well, a boundary condition of $8000 \mathrm{Scm}^{3} \mathrm{~min}^{-1}$ of air injection rate in the first $190 \mathrm{~min}$ is assigned. Thereafter, the air injection rate was increased to $10,667 \mathrm{Scm}^{3} \mathrm{~min}^{-1}$. In the case of 2VI wells, the air injection rate via each VI well is half of the total whilst in the case of the HI well, the total air injection rates were sent via the vertical arm of the well so that the air exits through the horizontal arm which has 17 perforations. In terms of pre-ignition heating, steam or electrical heater was used with appropriate boundary condition identified hereon. For models A and C, steam containing the equivalent amount of heating rate in model B (i.e. $2115 \mathrm{~J} \mathrm{~min}^{-1}$ per gridblock) was injected at a rate of $21.17 \mathrm{~cm}^{3} \mathrm{~min}^{-1}$ cold water equivalent (CWE) for a period of $28 \mathrm{~min}$ in each of the two models. Then, in each model, electrical heater/ignitor was used for $2 \mathrm{~min}$ to further increase the temperature of the inlet zone of the injectors and subsequently to initiate the combustion. With regard to heat loss, heat loss parameters are specified for the overburden and underburden. However, in all the horizontal-vertical sides (i.e. sideways areas), no heat loss is assumed. Since no matter crosses the overburden and underburden, the heat loss via them will be due to conduction only.

\section{Optimum grid block sizes selection}

For the sake of completeness, sensitivity of the simulation results against grid block sizes is investigated thoroughly as exemplified by study in Rabiu Ado (2017). In total, 38,000 grid blocks (i.e. for reservoir and discretised wellbore combined) are found to be sufficient in terms of capturing the full physics of the combustion front and taking the optimum computational time to do so. The total computational time is 2 h, 54 min when dynamic gridding was not used. However, it is found that all the key performance parameters for studying the THAI process are insensitive to the use of dynamic gridding. Therefore, it is worth pointing out here that the dynamic grid block refinement and de-refinement functionality in the CMG STARS (i.e. DYNAGRID) was used so that savings were made in terms of avoiding unnecessary calculations that would lead to taking more computational time. As a result, the computational time for each of the three models is $1 \mathrm{~h}, 58 \mathrm{~min}$.

\section{Results and discussions}

In order to fully use the key economic and safety indicators to decisively conclude the best or optimum well configurations together with best or optimum pre-ignition heating method, the following parameters as predicted by the models, which are derived from the validated model, are presented, analysed, discussed and compared:

(i) Oil production rate,

(ii) Cumulative oil produced and thus recovered,

(iii) Peak temperature, and

(iv) Produced oxygen concentration

No two- or three-dimensional profiles are considered here because they have already been analysed and discussed in multiple previous studies.

\section{Oil production rate}

To reiterate, model A consists of two vertical injection wells with a horizontal producer well (2VIHP) configured in a staggered line drive (SLD) pattern. In it, steam is the method of PIHC. For models B \& C, the horizontal injector well with a horizontal producer well (HIHP) are configured in an SLD arrangement. Electric heating is used for the PIHC in 
model B whilst steam is used in model C. Given the aforeexplained, models $\mathrm{A}$ and $\mathrm{C}$ are compared first since they both use steam for pre-ignition heating and that their only differences in terms of setting are the wells geometry and configuration. Onwards, models B \& C are compared as they both have the same wells geometry and arrangements but differ in the method of pre-ignition heating.

\section{Pre-ignition heating period}

Due to the spread of $\mathrm{HI}$ well in model $\mathrm{C}$ and thus having one of the perforations directly in the same plane as the HP well, oil production began just 10 min after the start of the PIHC. In the case of model A however, there is a delay by $5 \mathrm{~min}$ (i.e. oil production began in model A $15 \mathrm{~min}$ after the initiation of PIHC) which is due to the fact that the mobilised oil from around the shoe of each VI well has to travel both vertically downward and laterally towards the mid-plane where the HP well is located. This implies that model A should take a little longer before oil production began during the start-up. Both models A \& C have their initial oil production rates instantaneously peaking to around $16 \mathrm{~cm}^{3} \mathrm{~min}^{-1}$ (Fig. 3). In model A, the rate remains roughly at that value until steam injection was stopped at $28 \mathrm{~min}$ and electrical heater/ignitor was used to rise the temperature to higher value just prior to air injection. Thereafter, due to absence of large momentum transfer to the already mobilised oil, the oil production rate dropped to a lowest value of $5 \mathrm{~cm}^{3} \mathrm{~min}^{-1}$ during the last 2 min of electrical heating just before ignition. However, in the case of model $\mathrm{C}$, the oil production rate dropped steadily from $16 \mathrm{~cm}^{3} \mathrm{~min}^{-1}$ at $10 \mathrm{~min}$ to 9 $\mathrm{cm}^{3} \min ^{-1}$ by $28 \mathrm{~min}$ (Fig. 3). As the steam pre-ignition was stopped and electrical heater/ignitor put on for the remaining 2 min of the PIHC, the oil rate in model $\mathrm{C}$ declined further to around $7.5 \mathrm{~cm}^{3} \mathrm{~min}^{-1}$. Therefore, in both models $\mathrm{A} \& \mathrm{C}$, fluid communication was successfully established during the PIHC. To check whether some steam is lost via channelling into the HP well especially in model $\mathrm{C}$, the cumulative oil production curves were compared at $30 \mathrm{~min}$. It is found that both models A \& C curves overlap each other around that region (see Fig. 4) thereby implying that the same cumulative quantity of oil is produced even though that the quantity mobilised in model A is evidently greater than that in model $\mathrm{C}$ as we shall see in the next section.

Now comparing models B \& C, it can be seen from Fig. 3 that oil production in model B began 20 min after the commencement of electrical heating, implying that it lags model C by $10 \mathrm{~min}$. This large lag can be attributed to two things: (i) heat transfer from the electrical heating is dominantly by conduction especially at early stages before hot mobilised oil mixes with the cold oil located below the electrically heated zone and near the toe of the HP well, and (ii) absence of pressure force or momentum transfer from other fluids like steam causes the mobilised hot oil to reach the HP well due to mainly gravity drainage. The oil production rate in model B began by shooting to $20.5 \mathrm{~cm}^{3} \mathrm{~min}^{-1}$ before descending slightly slowly, reaching $17.5 \mathrm{~cm}^{3} \mathrm{~min}^{-1}$ at $28 \mathrm{~min}$ (Fig. 3). Thereon, it further declined but this time sharply to around $11 \mathrm{~cm}^{3} \mathrm{~min}^{-1}$ at $30 \mathrm{~min}$ (i.e. the end of the PIHC period). It is believed that the decline is caused by the fact that all the mobilisable oil in direct contact with the electrical heater/ ignitor has already been displaced and drained and that the
Fig. 3 Oil production rates versus time for the three models. The arrow pointing vertically upward indicates the time when the air injection rate was increased by $33.33 \%$

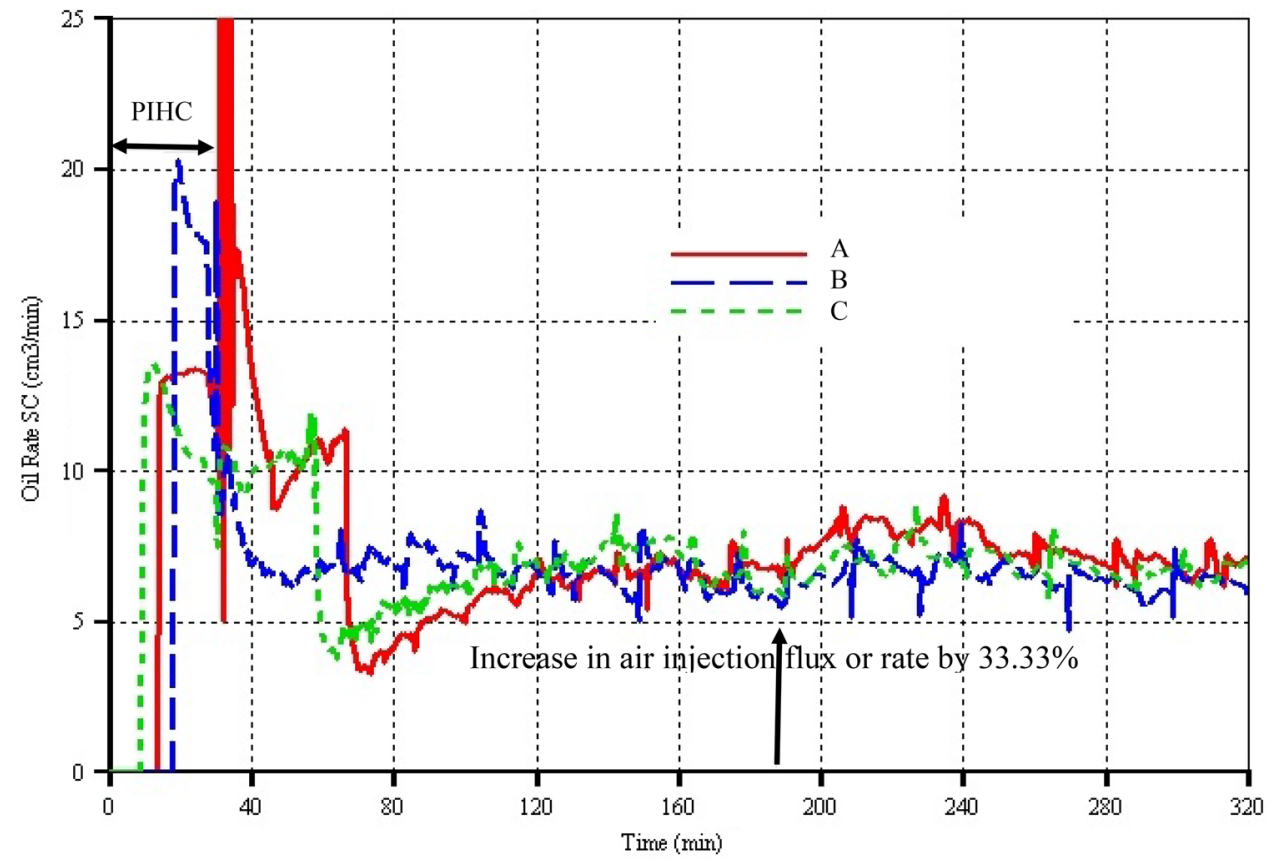


Fig. 4 Cumulative oil production curves versus time for the three models. The arrow pointing vertically upward indicates the time when the air injection rate was increased by $33.33 \%$

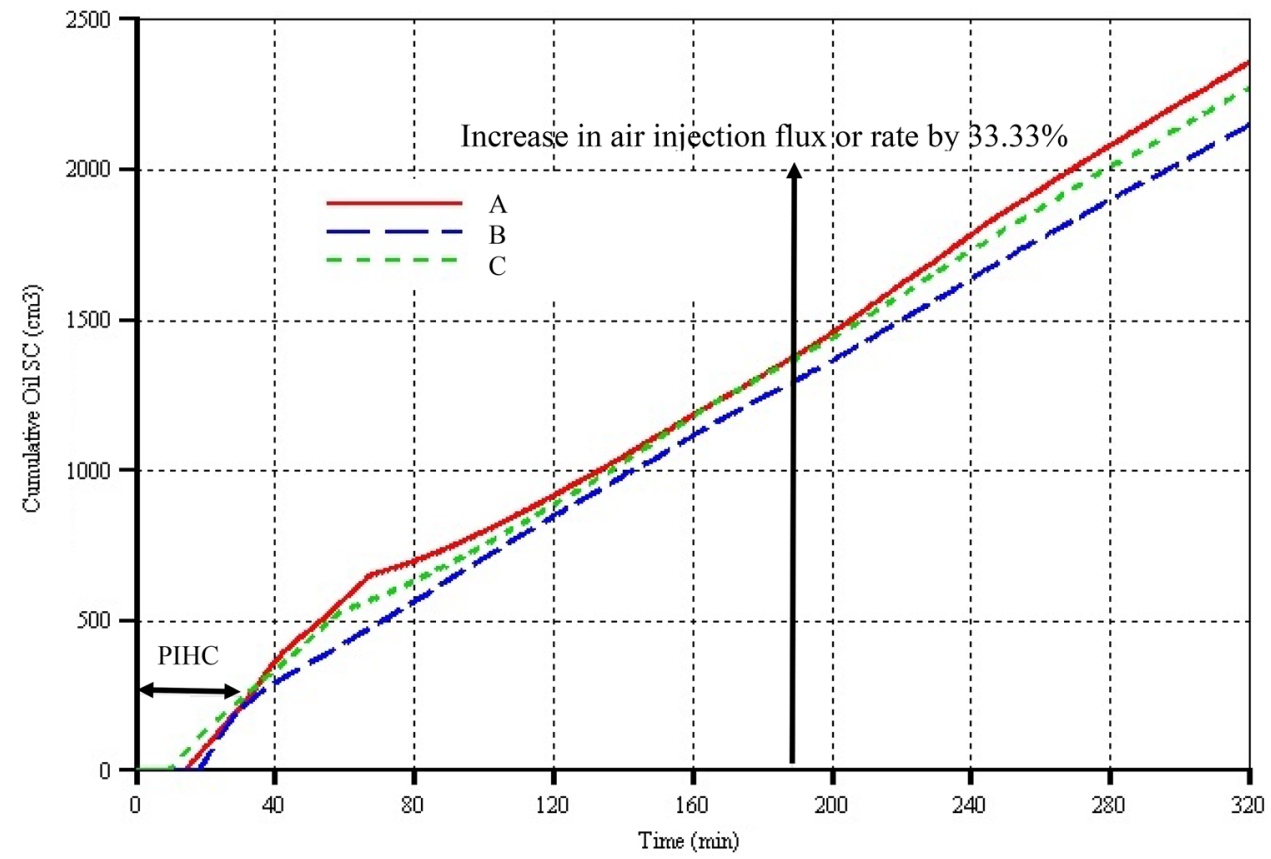

to-be-mobilised oil in the cold oil zone is thus not in direct contact with the electrical heater/ignitor. Over the $10 \mathrm{~min}$ of oil production in the PIHC phase in model $\mathrm{B}$, its oil rates are higher, sometimes even twice, than those in model $\mathrm{C}$. That means, the higher oil rates in model $\mathrm{B}$ could counter and balance the oil produced in model $\mathrm{C}$. This is exactly the case as reflected in the cumulative oil production curves where, by $30 \mathrm{~min}$, cumulatively, the same quantity of oil is recovered in both models (see Fig. 4). Therefore, in terms of start-up, in all the three models, it can be concluded that the same quantity of oil is cumulatively recovered by the end of the PIHC (Fig. 4). However, it is clearly determined that realisation of return on investment will be delayed by days or even months in real field operations where both models A \& B start-up methods and wells configurations are used. The best model in terms of early production is model $\mathrm{C}$ which is followed by A which in turn is followed by model B. The latter is the worst because the heat transfer is mainly by conduction, and consequently in the field, it is expected that longer than economically profitable period will be taken to establish fluid communication between the wells if model B settings are to be used. Therefore, during start-up, ultimately, steam injection instead of electrical heating should be used for the pre-ignition heating. But, this is just about the information from the start-up. The question that ought to be asked and answered is that: what about maintenance of optimal operations throughout the lifetime of the project?

\section{Combustion period}

Upon electrical heating for the $2 \mathrm{~min}$ (i.e. from 28 to $30 \mathrm{~min}$ for models A \& C) and injection of air together with electrical ignition in all the models, instantaneous increase in oil production rates can be seen in Fig. 3, ranging from very steep, moderately sharp, and slightly abrupt in models A, B, and $C$ respectively. These took place for the reason that the already mobilised partially upgraded oil that has not drained into the HP well was swept and forced to drain due to gas momentum transfer. However, the sudden rapid increase in the oil rate in model $\mathrm{A}$ is peculiar and merits further attention as it lasts for around $5 \mathrm{~min}$ (i.e. from 30 to $35 \mathrm{~min}$ ). This is caused due to the fact that both laterally to the left of VI well 1 and to the right of VI well 2, there were already mobilised oils that the relatively very low steam injection rate (i.e. $10.585 \mathrm{~cm}^{3} \mathrm{~min}^{-1}$ per VI well) could not reach to sweep them. Similarly, for model B, the already mobilised oil that did not drain due to absence of push from another fluid was swept by the large volume of gas leaving the combustion zone. Furthermore, for both models A \& B, there were small concentrations of the immobilised oil pseudo-component left surrounding the inlet zone of the combustion cell. Partly, also that is why the oil production rates increased correspondingly with the increase in their peak temperatures (see Fig. 5) respectively. For model C, the increase in oil production rate was comparatively smaller. This is as a result of the fact that low volume flow rate of steam enters the combustion cell via each of the 17 perforations in the horizontal arm of the HI well. Moreover, larger area of the reservoir is affected by the steam due to convection being the 
Fig. 5 Peak temperatures versus time for the three models. The arrow pointing vertically upward indicates the time when the air injection rate was increased by $33.33 \%$

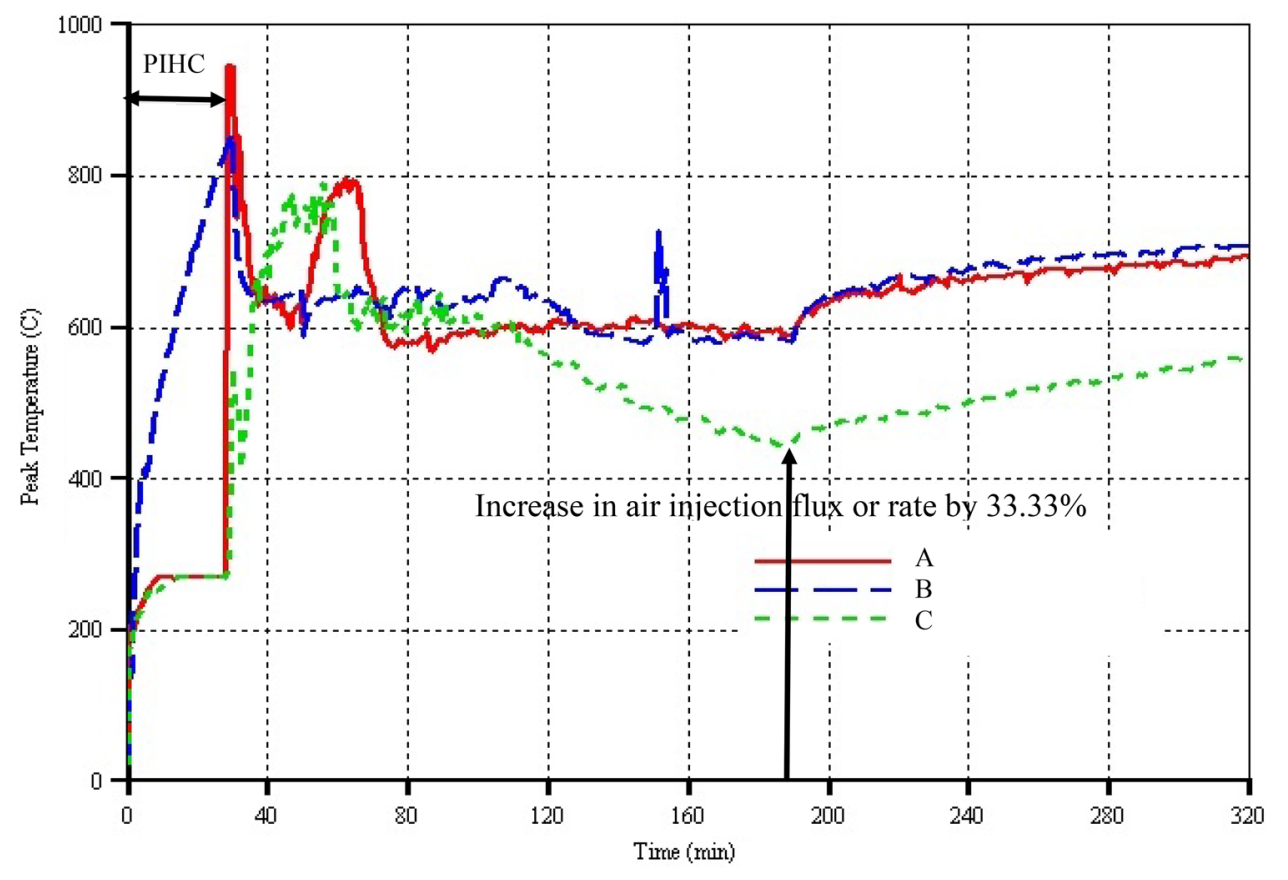

dominant mechanism of heat transfer thereby causing very high concentration of heavier fractions to remain around the HI well. These resulted in them consuming more energy to effect thermal cracking and at the same time for the combustion to be sustained (see Fig. 5 where the peak temperature of model $\mathrm{C}$ is the lowest between 30 and $35 \mathrm{~min}$ ).

Beyond 35 min model $\mathrm{A}$ and $\mathrm{C}$ predicted decrease, then increase, and then later decrease in the oil production rates until they reach minimums of $3.5 \mathrm{~cm}^{3} \mathrm{~min}^{-1}$ at around $75 \mathrm{~min}$ and $4 \mathrm{~cm}^{3} \mathrm{~min}^{-1}$ at around $65 \mathrm{~min}$ for models $\mathrm{A}$ and $\mathrm{C}$ respectively. Model $\mathrm{B}$ predicted decrease in the oil production rate over 35 to $50 \mathrm{~min}$ period, touching a minimum value of $6.5 \mathrm{~cm}^{3} \mathrm{~min}^{-1}$ at the latter time (Fig. 3). This dynamic or transient behaviour is associated with the injected air cooling effect in which there is competition between using the high-temperature oxidation (HTO) heat of the combustion zone for upstream heating of the entering air or for downstream heating of the different physicochemical zones to continue to achieve thermal cracking upgrading and mobilisation of cold oil. Past the minimum points in each model, there was steady increase in the oil rates in models $\mathrm{A}$ $\& \mathrm{C}$, with that of the former below that of the latter between 70 and $120 \mathrm{~min}$. For model B, past the minimum oil production rate to around $180 \mathrm{~min}$, the oil rate steadied out at an average value of $\approx 7 \mathrm{~cm}^{3} \mathrm{~min}^{-1}$ before slightly decreasing and then increasing slowly and flattening at an average of $\approx 7 \mathrm{~cm}^{3} \mathrm{~min}^{-1}$ again up to the end of the dry combustion period (Fig. 3). Models A \& C have similar trends as that in $\mathrm{B}$ with the exception of oil production rate in model $\mathrm{A}$ which lies above those of B and C from 190 to $320 \mathrm{~min}$. Likewise, over the same time range, that of model $\mathrm{C}$ lies above that of model B. In general, it can be concluded that steady state is achieved from around $110 \mathrm{~min}$ in each model, and that although all the models dynamically responded to the increase in air injection rate, no profitable or appreciable increase in oil rates is achieved due to the increase in the air injection flux. This finding has been observed from Kerrobert field data in which Wei et al. (2020b) found nonlinear relationship and in some cases no relationship between air injection rate and oil production rate. Therefore, optimum air injection rate must be determined so that unnecessary spending of operating cost is avoided. Also, it is worth pointing that any required increase in air injection rate must only be performed after the combustion front is fully established and steady fluids productions are realised. Clearly, and as reflected in the cumulative oil production curves of Fig. 4, model A has higher oil production rates after the increase in air flux, and thus, it can be concluded that for long-term projects, model A settings and wells configuration should be used. However, this is not decisively conclusive because there are other critical parameters that must be analysed.

\section{Cumulative oil production}

In each model, roughly $250 \mathrm{~cm}^{3}$ of oil is recovered by the end of the PIHC. This implies that the same quantity of energy was added and the same reservoir volume was swept by the pre-ignition heat. However, as mentioned earlier, the oil mobilisation inside the combustion cell is model dependent and at the start of ignition, the remaining unproduced mobilised oil was forced out in each model. In fact, the large quantity of it can be seen to have caused the model A curve

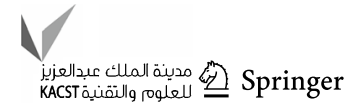


(Fig. 4) to have bigger slope between 40 and $80 \mathrm{~min}$. Thereafter to around 145, curve A lies above those of models B $\&$ C. Between 145 and 200 min, curves A and C overlapped before then diverging, with curve A lying above $\mathrm{C}$ for the rest of the dry combustion period of $320 \mathrm{~min}$. That convergence can be ascribed to the fact that from 80 to $160 \mathrm{~min}$, oil production rates in $\mathrm{C}$ are greater than in $\mathrm{A}$ which lead to curve $\mathrm{C}$ progressively moving towards $\mathrm{A}$ until the reverse has happened. However, this behaviour of model $\mathrm{C}$ is counter intuitive especially when the fact that from $110 \mathrm{~min}$ onwards, the peak temperature of model $\mathrm{C}$ lies below that of model A by up to $150^{\circ} \mathrm{C}$ (Fig. 5). This finding has placed question mark over the use of peak temperature to adjudge the overall quality of burning in the combustion front. Therefore, one of the major findings of this work is the fact that peak temperature does not, in certain situations, provide the measure of the efficient propagation of combustion front. This is because the simulator or even thermocouple in practical settings gives the highest value of the temperature at one single point relative to all remaining other points. As an example, consider the combustion front to have fingers such that at the leading edge of one finger, it encounters very large concentration of coke that presence of sufficient concentration of oxygen leads to large quantity of heat generation which will of course be reflected by the change in the temperature at that location. Therefore, the use of peak temperature will not tell us anything about other locations where the burning is in reality barely detectable. To summarise, in certain situations, the oil production rates, and thus the cumulative oil production, are not proportional to the peak temperature. From 30 to $320 \mathrm{~min}$, curve B lies below those of models A \& $\mathrm{C}$ thereby implying that oil production rates in the former are generally lower than in the latter two models. This is despite the fact that model B's peak temperature is mostly higher than that of model $\mathrm{C}$ by up to $150{ }^{\circ} \mathrm{C}$. Overall, a higher cumulative oil recovery of 2350 $\mathrm{cm}^{3}$ is obtained in model A which is greater than those of B and $\mathrm{C}$ by $9.6 \%$ and $4.3 \%$, respectively. Therefore, based on this, it can be concluded that model $\mathrm{A}$ is more efficient and thus profitable.

\section{Peak temperature}

From the peak temperature curves (Fig. 5), it can clearly be seen that at 28 to $30 \mathrm{~min}$, both models $\mathrm{A}$ and $\mathrm{C}$ have very large increase in peak temperature, with that of the former being substantially higher, reaching up to $950{ }^{\circ} \mathrm{C}$ compared to the $530{ }^{\circ} \mathrm{C}$ in the latter. For model $\mathrm{B}$, the peak temperature increased comparatively gradually, reaching $850{ }^{\circ} \mathrm{C}$ by the end of $30 \mathrm{~min}$ of PIHC. This is because conduction was the dominant mechanism of heat transfer during the PIHC of model B. On gas injection and just before combustion is started, an injected air cooling effect can be observed in all models. This finding has been observed in the field where heat consumption could not momentarily be balanced by the heat being generated (Wei et al. 2020b). Once combustion is started, the peak temperature of model A continues to decrease until around $50 \mathrm{~min}$ when it raised sharply reaching a new high value of $800{ }^{\circ} \mathrm{C}$ at $65 \mathrm{~min}$ before declining again and steadying out at an average of $600{ }^{\circ} \mathrm{C}$ until just before increase in air injection flux.

In model $\mathrm{C}$, just immediately combustion was started, there is sharp increase in peak temperature, climbing to $800{ }^{\circ} \mathrm{C}$ at $58 \mathrm{~min}$ before falling rapidly and steadying out at an average of $650{ }^{\circ} \mathrm{C}$ until $110 \mathrm{~min}$. Beyond that, the peak temperature declines steadily, hitting $440{ }^{\circ} \mathrm{C}$ at $190 \mathrm{~min}$ before picking-up again after increase in air injection flux. In model $\mathrm{B}$, the peak temperature more or less steadied out at an average value of $640{ }^{\circ} \mathrm{C}$ until $120 \mathrm{~min}$. Thereafter, it declined slightly before settling at around $600{ }^{\circ} \mathrm{C}$ up to $190 \mathrm{~min}$. Just before $160 \mathrm{~min}$, a spike in the peak temperature of model B, which does not appear in models $\mathrm{A}$ and $\mathrm{C}$, indicates the time when the combustion front has reached the toe of the horizontal producer (HP) well where there was a very high concentration of coke that lead to higher rate of heat generation and hence higher peak temperature. Once the coke at the toe was fully consumed, which appeared to have taken 15 min (Figs. 5, 6), oxygen production began. This is another major finding in this study which is similar to experimental observation (Xia and Greaves 2002). In model A, it simply means that the combustion did not reach the toe of the HP well from either of the two vertical injectors due to the lateral distance separating them from the toe of the HP well. Similarly, in C, it appears that although the combustion front has reached the toe of the HP well, the steaming during the PIHC has washed out most of the oil there to the extent that the concentration of the coke is generally lower and thus did not result in spike formation on the peak temperature curve. Like in model B, oxygen production in model $\mathrm{C}$ began at around $163 \mathrm{~min}$ (Fig. 6), indicating that indeed, the combustion front has reached the toe and has started to propagate along the HP well.

Immediately when air injection flux is increased by a factor of $\frac{4}{3}$, the peak temperatures in models A and B increased gradually whilst overlapping each other before slightly diverging with model $\mathrm{B}$ laying above $\mathrm{A}$ until the end of the dry combustion time (i.e. $320 \mathrm{~min}$ ). The peak temperature in model $\mathrm{C}$ also trends similarly whilst laying below those in $\mathrm{A}$ and $\mathrm{B}$ by up to $150{ }^{\circ} \mathrm{C}$ until the end of the dry combustion time. In general, what makes the peak temperature in model $\mathrm{C}$ for most of the combustion time to lie below those of $\mathrm{A}$ and $\mathrm{B}$ is additionally the fact that coke concentrations ahead of the combustion front are generally lower due to significant displacement of oil especially between 75 and 160 min (Fig. 3). Therefore, that makes the rate of the HTO 
Fig. 6 Produced oxygen mole fraction curves versus time for the three models. The arrow pointing vertically upward indicates the time when the air injection rate was increased by $33.33 \%$

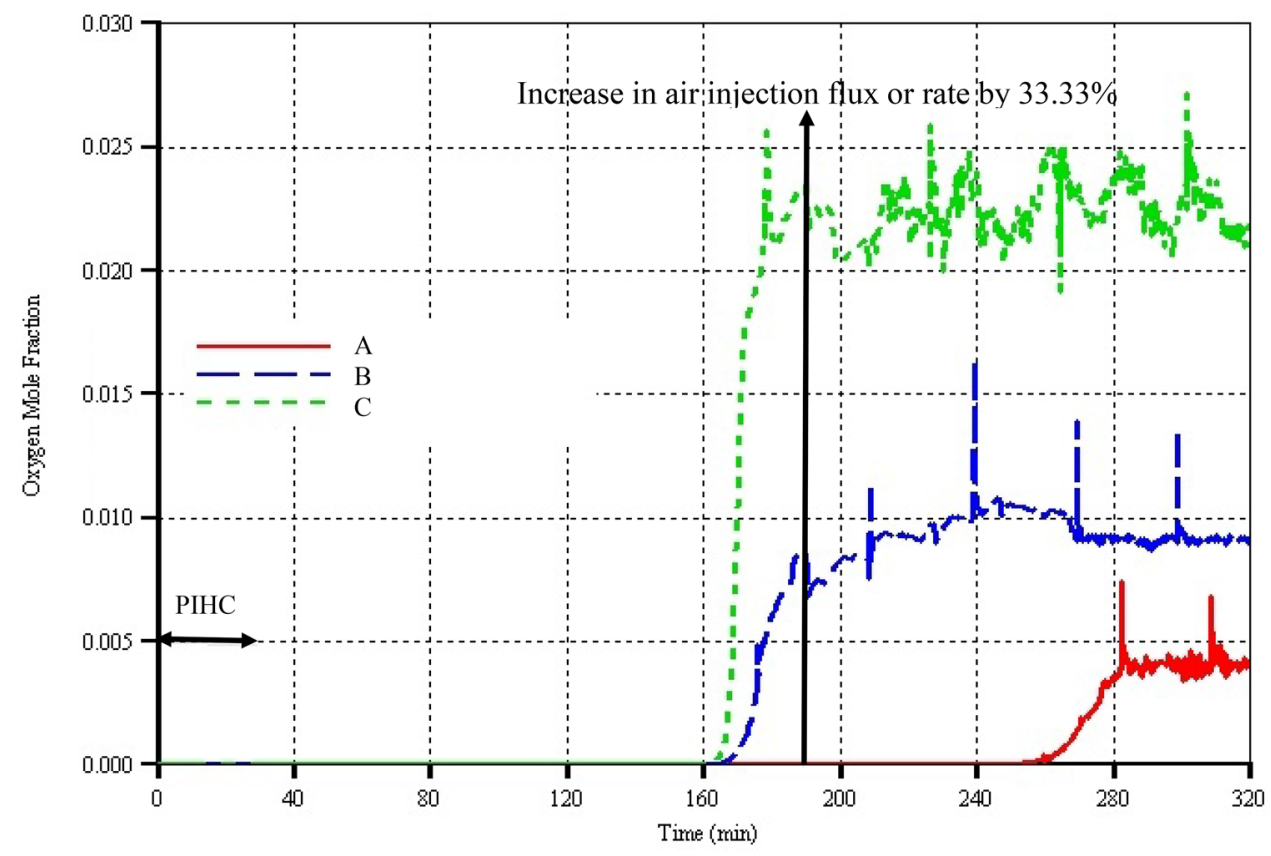

reaction and thus rate of heat generation lower, leading to lower peak temperatures. Another reason could be due to small amount of oxygen channelling from the toe and heel of the horizontal injector (HI) well respectively. However, the question that might be asked is about the delay in the start of oxygen production if it indeed was channelling from around $110 \mathrm{~min}$. And the answer is the fact that it had to displace water in the cold oil zone before it can reach the heel of the HP well and get produced from there.

In conclusion, although it is now discovered that the peak temperature cannot in all settings tell how healthy a combustion front is, it has revealed that model A does indeed have far more stable, safer, and efficient combustion front propagation due to the maintenance of very high peak temperatures throughout.

\section{Produced oxygen concentration}

To reiterate, in models $\mathrm{B}$ and $\mathrm{C}$, oxygen production began at 163 and 165 min respectively (Fig. 6). However, in the latter, it initially jumped to $2.5 \mathrm{~mol} \%$ before it oscillates between 1.9 and $2.75 \mathrm{~mol} \%$ for the rest of the combustion period. The oscillatory nature of the produced oxygen could be attributed to variabilities of coke concentrations along and around the HP well even though at least three reasons for the course of oxygen production in model $\mathrm{C}$ have been identified and explained in the preceding section. These concentrations are high enough to cause corrosion in the long term or even to burn inside the HP well which could lead to explosion. These findings are in accordance with conventional ISC field data (Sharma et al. 2021).
In the case of model $\mathrm{B}$, oxygen production is due to propagation of combustion front along the HP well only and since it has higher coke concentrations and peak temperature, the maximum concentration of the produced oxygen is just a little over $1 \mathrm{~mol} \%$ with the exception of five sharp spikes that might have been caused to appear due to the very small time step sizes during the numerical simulations. This is unlike in physical experiments where sampling rate is lower. It is worth noting that at around $270 \mathrm{~min}$, the concentration of the produced oxygen in model B has dropped to $0.9 \mathrm{~mol} \%$ and remained steady thereafter (Fig. 6). This could be an indicator that in the long run, breakthrough can only take place when oil production rates become uneconomical due to the combustion front nearing the heel of the HP well. In model A, oxygen production began at around $260 \mathrm{~min}$ with the maximum concentration of just around $0.4 \mathrm{~mol} \%$ (Fig. 6), and it appears to have reached steady state value by remaining constant till the end of the combustion time. This concentration is very low and is highly unlikely that it will pose safety or operational problems. It might be caused by creation of very narrow channel due to presence of very low or even zero concentration of coke in that zone.

To conclude, model A is by far more efficient in terms of burning quality of combustion, more stable, and safer in terms of concentration of oxygen in the produced gas stream. This is then followed by model B. Model C is unstable, unsafe, and inefficient in both the short and long terms. 


\section{Conclusion}

The THAI process is yet to be technically and economically well proven despite pilot and semi-commercial operations. Some studies concluded using field data that THAI is a low-oil-production-rate process. However, no study has thoroughly investigated the simultaneous effects of start-up methods and wells configuration on both the short and long terms stability, sustainability, and profitability of the process. Using THAI validated model, three models having a horizontal producer well arranged in a staggered line drive configuration with the all injector wells are simulated using CMG STARS. Model A has two vertical injectors via which steam was used for pre-ignition heating, and models B and C each has a horizontal injector via which electrical heater and steam were, respectively, used for pre-ignition heating. It is found that during start-up, ultimately, steam injection instead of electrical heating should be used for the pre-ignition heating especially with the two vertical injectors. Clearly, it is shown that model A has higher oil production rates after the increase in air flux and also has a higher cumulative oil recovery of $2350 \mathrm{~cm}^{3}$ which is greater than those of models B and C by $9.6 \%$ and $4.3 \%$ respectively. Thus, it can be concluded that for long-term projects, model A settings and wells configuration should be used. Although it is now discovered that the peak temperature cannot in all settings tell how healthy a combustion front is, it has revealed that model A does indeed have far more stable, safer, and efficient combustion front burning quality and propagation due to the maintenance of very high peak temperatures of mostly greater than $600{ }^{\circ} \mathrm{C}$ and very low concentrations of produced oxygen of lower than $0.4 \mathrm{~mol} \%$ compared to up to $2.75 \mathrm{~mol} \%$ in model $\mathrm{C}$ and $1 \mathrm{~mol} \%$ in model B. Conclusively, since drilling of, and achieving uniform air distribution in horizontal injector (HI) well in actual field reservoir are costly and impracticable at the moment, and that electrical heating will require unphysically long time before mobilised fluids reach the HP well as heat transfer is mainly by conduction, these findings have shown decisively that the easy-and-cheaperto-drill two vertical injector wells configured in a staggered line drive pattern with the horizontal producer well should be used, and steam is thus to be used for pre-ignition heating.

Funding The author gratefully acknowledges the Deanship of Scientific Research (DSR) at King Faisal University for financially supporting the publication of this work under the Nasher Track 2021 with Research Grant Number of 216073.

\section{Declaration}

Conflict of interest I declare that there is no conflict of interest.
Open Access This article is licensed under a Creative Commons Attribution 4.0 International License, which permits use, sharing, adaptation, distribution and reproduction in any medium or format, as long as you give appropriate credit to the original author(s) and the source, provide a link to the Creative Commons licence, and indicate if changes were made. The images or other third party material in this article are included in the article's Creative Commons licence, unless indicated otherwise in a credit line to the material. If material is not included in the article's Creative Commons licence and your intended use is not permitted by statutory regulation or exceeds the permitted use, you will need to obtain permission directly from the copyright holder. To view a copy of this licence, visit http://creativecommons.org/licenses/by/4.0/.

\section{References}

Ado MR (2020a) Impacts of kinetics scheme used to simulate toe-toheel air injection (THAI) in situ combustion method for heavy oil upgrading and production. ACS Omega 5:1938-1948. https://doi. org/10.1021/acsomega.9b03661

Ado MR (2020b) A detailed approach to up-scaling of the toe-to-heel air injection (THAI) in situ combustion enhanced heavy oil recovery process. J Pet Sci Eng 187:106740. https://doi.org/10.1016/j. petrol.2019.106740

Ado MR (2020c) Predictive capability of field scale kinetics for simulating toe-to-heel air injection heavy oil and bitumen upgrading and production technology. J Pet Sci Eng 187:106843. https://doi. org/10.1016/j.petrol.2019.106843

Ado MR (2020d) Simulation study on the effect of reservoir bottom water on the performance of the THAI in situ combustion technology for heavy oil/tar sand upgrading and recovery. SN Appl Sci 2:1-16. https://doi.org/10.1007/s42452-019-1833-1

Ado MR (2020e) Effect of reservoir pay thickness on the performance of the THAI heavy oil and bitumen upgrading and production process. J Pet Explor Prod Technol 10:2005-2018. https://doi.org/ 10.1007/s13202-020-00840-5

Ado MR (2021) Improving oil recovery rates in THAI in situ combustion process using pure oxygen. Upstream Oil Gas Technol 6:100032. https://doi.org/10.1016/j.upstre.2021.100032

Ado MR, Greaves M, Rigby SP (2019) Numerical simulation of the impact of geological heterogeneity on performance and safety of THAI heavy oil production process. J Pet Sci Eng 173:1130-1148. https://doi.org/10.1016/j.petrol.2018.10.087

Attanasi ED, Meyer RF (2010) Natural bitumen and extra-heavy oil [WWW Document]. 2010 Survey of Energy Resources. http:// pubs.er.usgs.gov/publication/70200473. Accessed 15 Feb 2021

British Petroleum (BP) (2020) Statistical review of World Energy [WWW Document]. https://www.bp.com/content/dam/bp/busin ess-sites/en/global/corporate/pdfs/energy-economics/statisticalreview/bp-stats-review-2020-full-report.pdf. Accessed 16 Nov 2020

Elahi SM, Scott CE, Chen Z, Pereira-Almao P (2019) In situ upgrading and enhanced recovery of heavy oil from carbonate reservoirs using nano-catalysts: upgrading reactions analysis. Fuel 252:262271. https://doi.org/10.1016/j.fuel.2019.04.094

Fatemi SM, Ghotbi C, Kharrat R (2009) Effect of wells arrangement on the performance of toe-to-heel air injection. Braz J Pet Gas 3:011-028

Gates ID (2010) Solvent-aided steam-assisted gravity drainage in thin oil sand reservoirs. J Pet Sci Eng 74:138-146. https://doi.org/10. 1016/j.petrol.2010.09.003

Gates ID, Larter SR (2014) Energy efficiency and emissions intensity of SAGD. Fuel 115:706-713. https://doi.org/10.1016/j.fuel.2013. 07.073 
Greaves M, Al-Shamali O (1996) In situ combustion ISC process using horizontal wells. J Can Pet Technol. https://doi.org/10. 2118/96-04-05

Greaves M, Tuwil AA, Bagci AS (1993) Horizontal producer wells in in situ combustion (ISC) processes. J Can Pet Technol. https://doi. org/10.2118/93-04-04

Greaves M, El-Sakr A, Xia TX, Ayasse C, Turta A (1999) Thai-new air injection technology for heavy oil recovery and in situ upgrading. In: Annual technical meeting. https://doi.org/10.2118/99-15

Greaves M, Xia TX, Turta AT (2008) Stability of THAI (TM) process - theoretical and experimental observations. J Can Pet Technol 47:65-73

Guo K, Li H, Yu Z (2016) In situ heavy and extra-heavy oil recovery: a review. Fuel 185:886-902. https://doi.org/10.1016/j.fuel.2016. 08.047

Hein FJ (2017) Geology of bitumen and heavy oil: an overview. J Pet Sci Eng 154:551-563. https://doi.org/10.1016/j.petrol.2016.11. 025

International Energy Agency (2020) World Energy Outlook [WWW Document]. https://www.iea.org/reports/world-energy-outlook2020. Accessed 29 Oct 2020

Li Y, Wang Z, Hu Z, Xu B, Li Y, Pu W, Zhao J (2020) A review of in situ upgrading technology for heavy crude oil. Petroleum. https://doi.org/10.1016/j.petlm.2020.09.004

Liang J, Guan W, Jiang Y, Xi C, Wang B, Li X (2012) Propagation and control of fire front in the combustion assisted gravity drainage using horizontal wells. Pet Explor Dev 39:764-772

Liu Z, Wang H, Blackbourn G, Ma F, He Z, Wen Z, Wang Z, Yang Z, Luan T, Wu Z (2019) Heavy oils and oil sands: global distribution and resource assessment. Acta Geol Sin Engl Ed 93:199-212. https://doi.org/10.1111/1755-6724.13778

Ma Z, Leung JY (2020) Efficient tracking of solvent chamber development during warm solvent injection in heterogeneous reservoirs via machine learning. SPE Canada Heavy Oil Conf. https://doi. org/10.2118/199917-MS

Meyer RF, Attanasi ED, Freeman PA (2007) Heavy oil and natural bitumen resources in geological basins of the world, U.S. Geological Survey Open-File Report 2007-1084. https://pubs.usgs. gov/of/2007/1084/

Mokrys IJ, Butler RM (1993) In situ upgrading of heavy oils and bitumen by propane deasphalting: the Vapex process. In: SPE production and operations symposium. https://doi.org/10.2118/ 25452-MS

Paitakhti Oskouei SJ, Moore RG, Maini B, Mehta S (2011) Feasibility of in situ combustion in the SAGD chamber. J Can Pet Technol 50:31-44

Petrobank (2007) IETP 01-019 Whitesands Experimental Project-2007 annual report [WWW Document]. https://open.alber ta.ca/dataset/06f18b06-8556-45ee-a654-3ff50f $25 \mathrm{f} 4 \mathrm{f} 5 /$ resource/ 4a1bc69b-6d92-4583-a503-52d36ccaeba9/download/ietp-no.01-019-whitesands-pilot-economics-2007-annual-report.pdf. Accessed 24 Feb 2021

Petrobank (2008) IETP 01-019 Whitesands Experimental Project-2008 annual report [WWW Document]. https://open.alber ta.ca/dataset/06f18b06-8556-45ee-a654-3ff50f25f4f5/resource/ 49c917de-7190-45a1-b92e-334b72a9aa67/download/01-019ietp-report-with-title-page.pdf. Accessed 24 Feb 2021

Petrobank (2009) IETP 01-019 Whitesands Experimental Projectfinal/annual (2009) report [WWW Document]. https://open.alber ta.ca/dataset/06f18b06-8556-45ee-a654-3ff50f25f4f5/resource/ 8c557fe6-b2a5-44cb-b58d-a27188a67731/download/ietp-appro val-01_019-final-and-2009-report.pdf. Accessed 24 Feb 2021

Rabiu Ado M (2017) Numerical simulation of heavy oil and bitumen recovery and upgrading techniques. University of Nottingham, Nottingham
Rabiu Ado M, Greaves M, Rigby SP (2017) Dynamic simulation of the toe-to-heel air injection heavy oil recovery process. Energy Fuels 31:1276-1284. https://doi.org/10.1021/acs.energyfuels.6b02559

Rabiu Ado M, Greaves M, Rigby SP (2018) Effect of pre-ignition heating cycle method, air injection flux, and reservoir viscosity on the THAI heavy oil recovery process. J Pet Sci Eng 166:94-103. https://doi.org/10.1016/j.petrol.2018.03.033

Shah A, Fishwick R, Wood J, Leeke G, Rigby S, Greaves M (2010) A review of novel techniques for heavy oil and bitumen extraction and upgrading. Energy Environ Sci 3:700-714. https://doi.org/ $10.1039 / \mathrm{b} 918960 \mathrm{~b}$

Sharma J, Dean J, Aljaberi F, Altememee N (2021) In situ combustion in Bellevue field in Louisiana-history, current state and future strategies. Fuel 284:118992. https://doi.org/10.1016/j.fuel.2020.118992

Shi L, Xi C, Liu P, Li X, Yuan Z (2017) Infill wells assisted in situ combustion following SAGD process in extra-heavy oil reservoirs. J Pet Sci Eng 157:958-970. https://doi.org/10.1016/j.petrol.2017.08.015

Turta A (2018) Toe-to-heel air injection (THAI) process [WWW Document]. https://www.insitucombustion.ca/Advanced_THAI_Broch ure.pdf. Accessed 24 Feb 2021

Turta A, Singhal A (2004) Overview of short-distance oil displacement processes. J Can Pet Technol 43:29-38

Turta A, Kapadia P, Gadelle C (2020) THAI process: Determination of the quality of burning from gas composition taking into account the coke gasification and water-gas shift reactions. J Pet Sci Eng 187:106638. https://doi.org/10.1016/j.petrol.2019.106638

Wei W, Rezazadeh A, Wang J, Gates ID (2020a) An analysis of toe-to-heel air injection for heavy oil production using machine learning. J Pet Sci Eng 197:108109. https://doi.org/10.1016/j.petrol.2020.108109

Wei W, Wang J, Afshordi S, Gates ID (2020b) Detailed analysis of toe-to-heel air injection for heavy oil production. J Pet Sci Eng 186:106704. https://doi.org/10.1016/j.petrol.2019.106704

Xi C (2016) The characteristics of high temperature in-situ combustion mode in intensive heterogeneous reservoir-a case study in Block HQ of Xinjiang Oilfield [WWW Document]. https://www. insitucombustion.ca/XinjiangISCAfterSteam_2016.pdf. Accessed 1 March 2021

Xia TX, Greaves M (2002) Upgrading athabasca tar sand using toeto-heel air injection. J Can Pet Technol 41:7. https://doi.org/10. 2118/02-08-02

Xia T, Greaves M (2006) In situ upgrading of athabasca tar sand bitumen using Thai. Chem Eng Res Des 84:856-864. https://doi.org/ 10.1205/cherd.04192

Xia TX, Greaves M, Turta AT (2002) Injection well-producer well combinations in THAI "toe-to-heel air injection". https://doi.org/ 10.2118/75137-MS

Xia T, Greaves M, Turta A (2005) Main mechanism for stability of THAI-toe-to-heel air injection. J Can Pet Technol 44:42-48

Zhang X, Liu Q, Fan Z, Liu Y (2019) Enhanced heavy oil recovery and performance by application of catalytic in situ combustion. Pet Sci Technol 37:493-499. https://doi.org/10.1080/10916466. 2018.1482333

Zhao DW, Wang J, Gates ID (2013) Optimized solvent-aided steamflooding strategy for recovery of thin heavy oil reservoirs. Fuel 112:50-59. https://doi.org/10.1016/j.fuel.2013.05.025

Zhao DW, Wang J, Gates ID (2014) Thermal recovery strategies for thin heavy oil reservoirs. Fuel 117:431-441. https://doi.org/10. 1016/j.fuel.2013.09.023

Zhao R, Yu S, Yang J, Heng M, Zhang C, Wu Y, Zhang J, Yue X (2018) Optimization of well spacing to achieve a stable combustion during the THAI process. Energy 151:467-477. https://doi.org/10. 1016/j.energy.2018.03.044

Publisher's Note Springer Nature remains neutral with regard to jurisdictional claims in published maps and institutional affiliations.

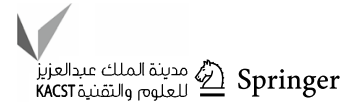

